\title{
Hypercholesterolemia is a risk factor for bioprosthetic valve calcification and explantation
}

\author{
Robert Saeid Farivar, MD, PhD \\ Lawrence H. Cohn, MD
}

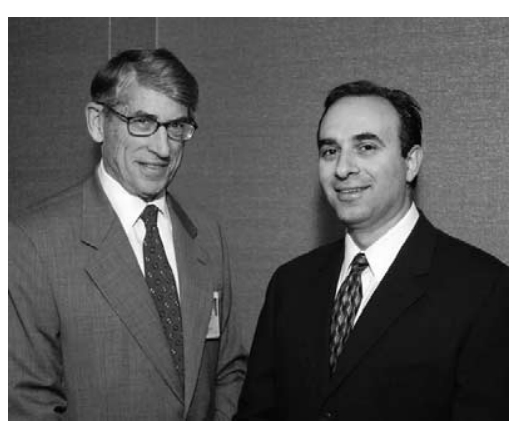

Drs Cohn and Farivar

See related articles on pages 939 and 965.

\footnotetext{
From the Division of Cardiac Surgery, Department of Surgery, Brigham \& Women's Hospital, Harvard Medical School, Boston, Mass.

Dr Farivar is a recipient of an individual National Research Service Award (F32HL6753902) from the National Institutes of Health.

Read at the Eighty-third Annual Meeting of The American Association for Thoracic Surgery, Boston, Mass, May 4-7, 2003.

Received for publication March 13, 2003; revisions requested April 8, 2003; revisions received April 14, 2003; accepted for publication April 21, 2003.

Address for reprints: Lawrence H. Cohn, MD, Division of Cardiac Surgery, Brigham \& Women's Hospital, 75 Francis St, Boston, MA 02115 (E-mail: 1cohn@ partners.org).

J Thorac Cardiovasc Surg 2003;126:969-76

Copyright $\odot 2003$ by The American Association for Thoracic Surgery

$0022-5223 / 2003 \$ 30.00+0$

doi:10.1016/S0022-5223(03)00708-6
}

Objective: There are pathophysiologic similarities between calcification and atherosclerosis. We wished to determine whether risk factors for atherosclerosis were linked to bioprosthetic valve calcification and dysfunction.

Methods: We performed a retrospective cohort study on 144 patients at a single institution who had bioprosthetic aortic or mitral valves removed, serum cholesterol levels recorded, and valve calcification assessed on the basis of hematoxylin and eosin staining and radiography of the valve. We also performed case-control analysis of a group of 66 patients whose tissue valves were explanted and compared them with an age- and position-matched group of 66 patients with similar duration of implantation. We also compared mean serum cholesterol levels.

Results: In the retrospective cohort study cholesterol $(P=.035)$, younger age at implantation $(P=.014)$, and coronary artery disease $(P=.017)$ were linked to calcification of the valve by means of univariate analysis. In stepwise multiple regression analysis only the mean serum cholesterol level was linked to calcification $(P=.02)$. Sex, hypertension, smoking, diabetes, and implant position were not linked to calcification. In the case-control analysis the mean serum cholesterol level of the explanted valve group was significantly higher (189 vs $163 \mathrm{mg} / \mathrm{dL}, P<$ .0001) than that of the group whose valves did not require explantation. For those whose serum cholesterol levels were greater than $200 \mathrm{mg} / \mathrm{dL}$, the odds ratio was 3.9 (95\% confidence interval, 1.7-8.9) for valve explantation.

Conclusions: Increased serum cholesterol level may be a risk factor for bioprosthetic valve calcification requiring explantation.

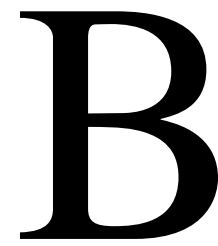

ioprosthetic valve replacement has improved the outcomes of patients with valvular heart disease. Tissue valves have central flow and a high freedom from thrombus formation, usually without the need for anticoagulation. However, most tissue valves are altered biologic materials that undergo degenerative processes. ${ }^{1,2}$

A study of the causes of valve failure necessitating reoperation at our institution has reported that sterile degeneration, or primary tissue failure, accounted for $74 \%$ of bioprosthetic valve failures. ${ }^{3}$ Primary tissue failure was most often related to calcification of the tissue cusps. Calcification was present in $86 \%$ of patients, and cuspal defects in $79 \%$ of bioprosthetic valves were removed for primary tissue failure. Seventy-five percent of valves with degenerative failure had both calcification and tears.

No medical therapy, as of yet, has been demonstrated to be effective in the prevention of the progression of bioprosthetic calcification. Recently, a compelling argument has been espoused demonstrating the similarities between calcific aortic sclerosis in the native valve and atherosclerosis. ${ }^{4,5}$ Chronic inflammatory changes in the leaflet, including cellular infiltration of macrophages and $\mathrm{T}$ lymphocytes and lipoprotein deposition in apposition to areas of calcification, has prompted investi- 
gation as to whether medical therapy can be applied to slow the progression of valvular failure.

Several studies have documented a correlation between lipids and calcification. Pohle and colleagues ${ }^{6}$ have documented that both coronary calcification and aortic valve calcification progress more rapidly in subjects with lowdensity lipoprotein (LDL) levels of greater than $130 \mathrm{mg} / \mathrm{dL}$. Callister and associates ${ }^{7}$ demonstrated that patients who reduced their cholesterol levels with lipid-lowering agents significantly reduced the progression of coronary calcification. In another study the risk factor that most significantly correlated with coronary calcification was LDL levels, and this was stronger than age, male sex, blood pressure, fasting insulin level, or smoking. ${ }^{8}$ Native aortic valve calcium accumulation, as assessed by means of electron beam computed tomography, is diminished by statin use. ${ }^{9}$

We hypothesized that serum cholesterol levels might be associated with increasing bioprosthetic valve calcification, as assessed by means of a retrospective cohort study. We also questioned whether increased serum cholesterol levels are associated with a higher incidence of valve explantation, as assessed by means of a case-control study.

\section{Methods}

For the cohort study, as well as for the case-control analysis, the Brigham \& Women's Hospital Institutional Review Board approved the study. Exclusion criteria included the following: (1) lack of serum cholesterol measurement; (2) a bioprosthetic valve in the tricuspid position; or (3) rapid valvular failure $(<1$ year, deemed to be due to a technical cause). No patients were known to have renal failure or secondary hyperparathyroidism. Total serum cholesterol levels were available in all study patients, and our laboratory's normal range is 140 to $230 \mathrm{mg} / \mathrm{dL}$. Because patients had multiple cholesterol measurements while the valve was in place, the mean serum cholesterol level was obtained by determining the average in any single year and then averaging together all years during which the valve remained implanted. Cholesterol values assayed during a period up to 1 month after cardiac surgery were discarded. Coronary artery disease was defined by a history of myocardial infarction, angioplasty, or cardiac catheterization identifying a greater than $50 \%$ stenosis. Diabetes mellitus was defined by a need for either oral or parenteral hypoglycemic agents. Hypertension was defined as medical treatment with more than one antihypertensive agent. Smoking was self-reported, and patients were divided into former smokers and smokers at the time of valve implantation.

\section{Historical Cohort}

We performed a retrospective cohort study of all patients referred to our single center over 10 years (1992-2002) for individuals who had their bioprosthetic aortic or mitral valves removed and who had serum cholesterol levels (excluding up to 1 month after valve surgery) measured during the period when the valve was in use. One hundred forty-four patients met the inclusion and exclusion criteria. We reviewed the medical records for the pathologic assessment of calcification at the time of explantation. Calcification was assessed by means of a combination of histologic and radiographic methods. Valves were radiographed for calcium and stained with hematoxylin and eosin after decalcification of the tissue for sectioning. A grading scheme of 0 to $4+$ was reported, with heavy calcification given a rating of $4+$ and no calcification given a rating of 0 .

\section{Case-Control Study}

We performed a case-control study of patients referred to our single center over 10 years (1992-2002) for individuals who had their bioprosthetic aortic or mitral valves removed and who had serum cholesterol levels measured while the valve was in place. Control subjects were matched to patients for (1) duration of valve survival, (2) age of the patient at the time of implantation (within 1-5 years of patient age), and (3) valve position (aortic vs mitral) by using the Brigham Cardiac Surgery Database. We matched patients against our computerized prospective database from 1992 onward, using a computerized sorting algorithm that first sorted by duration of survival (for control subjects) or removal (for patients), then by age at implantation, and finally by position. Fewer patients are enrolled in the case-control analysis than in the cohort analysis because of adequate statistical power with approximately 70 patients in each group and difficulty in finding adequate control subjects for all patients. It should be noted that the same patients in the cohort analysis were used as patients here. Matched control subjects, however, are a different group of patients and are not represented in the group of patients in the cohort analysis.

Patients and control subjects were temporally mismatched, on average, by 6 years because the mean \pm SD year of birth for the patients was $1930 \pm 1.8$ versus $1936 \pm 1.7$ for control subjects $(P$ $<.001)$. Thus the age of the patient at implantation is matched, but patients represent an earlier surgical population. We performed 2 additional analyses to investigate whether this had any effect on mean cholesterol levels between patients and control subjects. First, we removed all pairs in which one or both members were taking statins to remove the confounding effects of these drugs (data not shown). Second, we reanalyzed patients by matching for year of operation (thus valves were implanted during the same year in both patients and control subjects), age of patient at implantation, and position. This effectively removed any possible confounding effects of changing medical-surgical practices, although it reduced our analyses to 22 patients.

\section{Statistical Analyses}

All analyses were carried out with the Statistica software package (version 5.5, Tulsa, Okla), and $P$ values are reported. For cohort analyses, we used the nonparametric test of correlation because calcification was not distributed in a normal manner (Table 1 for the distribution of calcification). We used the Spearman rank order coefficient to compare ordered categoric data (eg, calcification) versus continuous data (eg, serum cholesterol level). To compare ordered categorical versus dichotomous data (eg, sex), we used the Wilcoxon rank sum test. All risk factors that had a $P$ value of less than .10 in the univariate analyses were also analyzed by means of stepwise multiple regression.

For case-control analysis, groups were examined by using a 2-tailed paired Student $t$ test, and all $P$ values are reported. The 
odds ratio for explantation was calculated for those whose serum cholesterol levels were greater than $200 \mathrm{mg} / \mathrm{dL}$.

\section{Results}

\section{Cohort Analysis}

Of the 144 patients who met study inclusion and exclusion criteria, $82(57 \%)$ were men (Table 1$)$. The mean \pm SD age at implantation was $55 \pm 12.9$ years. Because the valves in this group were implanted in aggregate from $1984.8 \pm 4.4$ and because these patients went on to have their valves explanted, they represent a younger population than those who are currently receiving tissue valves. The youngest patient in this series to receive a bioprosthetic valve was 23 years of age, and the oldest was 79 years of age (age at the time of implantation). The mean valve survival was $10.9 \pm$ 4.4 years, ranging from 1 year to 21 years. Ninety-seven (67\%) patients had valves placed in the aortic position, and $47(33 \%)$ had valves placed in the mitral position. Coronary artery disease was present in $69(48 \%)$ patients, diabetes mellitus was present in 26 (18\%) patients, and hypertension was present in $87(60 \%)$ patients. The mean cholesterol level of the group $(n=144)$ was $191 \pm 42 \mathrm{mg} / \mathrm{dL}$. Eighteen (13\%) patients had their valves removed without any calcification. The distribution of the calcification is shown in Table 1 , and the majority of patients had 1 to $2+$ calcification. This non-Gaussian distribution of calcification led us to use nonparametric analyses of correlation. Causes of failure included leaflet tear (91 [63\%] patients), degeneration (40 [28\%] patients), bacterial endocarditis (5 [3.5\%] patients), and others, including perforation, thrombosis, or paravalvular leak (8 [5.55] patients combined). Removing patients with bacterial endocarditis and other causes still resulted in a significant correlation between calcification and cholesterol level ( $r=0.169, P=.04)$. These causes might have coexisted with valvular calcification, and this is in agreement with previous reports from our institution. ${ }^{3}$

Stepwise multiple regression was performed on all dependent variables with a significance of less than .10 determined by means of univariate analysis. Thus implant age, coronary artery disease, average serum cholesterol level, and diabetes mellitus were used as dependent variables in predicting calcification. Of the 4 dependent variables, only average cholesterol level achieved significance $(P=.02)$ in the multiple regression (Table 2).

\section{Case-Control Analysis}

Sixty-six patients met study inclusion and exclusion criteria as patients in the explanted valve group, and 32 $(48 \%)$ were male (Table 3$)$. The mean \pm SE age at implantation was $57.6 \pm 1.7$ years. The youngest patient in this series to receive a bioprosthetic valve was 24 years of age, and the oldest was 79 years of age (age at the time of implantation). The mean valve survival was $7.3 \pm 0.3$ years, ranging from 1 year to 9 years. Patient age, dura-
TABLE 1. Cohort analysis

\begin{tabular}{|c|c|c|}
\hline Parameter & Mean (SD) & $\begin{array}{c}\text { Range (min-max) } \\
\text { or } \%\end{array}$ \\
\hline Age (y) & $55(12.9)$ & $23-79$ \\
\hline $\mathrm{n}$ & 144 patients & Not applicable \\
\hline \multirow[t]{2}{*}{ Sex } & 82 male & $57 \%$ \\
\hline & 62 female & $43 \%$ \\
\hline Valve survival (y) & $10.9(4.4)$ & $1-21$ \\
\hline Valve position & $\begin{array}{l}97 \text { aortic } \\
47 \text { mitral }\end{array}$ & $\begin{array}{l}67 \% \\
33 \%\end{array}$ \\
\hline $\begin{array}{l}\text { Mean serum } \\
\text { cholesterol } \\
\text { level }\end{array}$ & $191 \mathrm{mg} / \mathrm{dL}$ (42) & $(93-308 \mathrm{mg} / \mathrm{dL})$ \\
\hline $\begin{array}{l}\text { Coronary artery } \\
\text { disease }\end{array}$ & 69 patients & $48 \%$ \\
\hline Diabetes & 26 patients & $18 \%$ \\
\hline Hypertension & 87 patients & $60 \%$ \\
\hline Statin use & 19 patients & $13 \%$ \\
\hline \multirow[t]{3}{*}{ Smoker } & No, 103 patients & $72 \%$ \\
\hline & Former, 13 patients & $9 \%$ \\
\hline & Yes, 28 patients & $19 \%$ \\
\hline \multirow{5}{*}{$\begin{array}{l}\text { Distribution of } \\
\text { calcification }\end{array}$} & 0,18 patients & $13 \%$ \\
\hline & $1+, 67$ patients & $46 \%$ \\
\hline & $2+, 34$ patients & $24 \%$ \\
\hline & $3+, 22$ patients & $15 \%$ \\
\hline & $4+, 3$ patients & $2 \%$ \\
\hline \multirow{4}{*}{$\begin{array}{l}\text { Classification of } \\
\text { valve failure }\end{array}$} & Leaflet tear, 91 patients & $63 \%$ \\
\hline & Degeneration, 40 patients & $28 \%$ \\
\hline & $\begin{array}{l}\text { Bacterial endocarditis, } 5 \\
\text { patients }\end{array}$ & $3.5 \%$ \\
\hline & $\begin{array}{l}\text { Other (perforation- } \\
\text { thrombosis or } \\
\text { paravalvular leak), } 8 \\
\text { patients }\end{array}$ & $5.5 \%$ \\
\hline
\end{tabular}

tion of valve survival (or until explantation), and position were all matched. Forty-three $(65 \%)$ patients had valves placed in the aortic position, and 23 (35\%) had valves placed in the mitral position. Coronary artery disease was present in $33(50 \%)$ patients, diabetes mellitus was present in $17(26 \%)$ patients, hypertension was present in $42(64 \%)$ patients, and $15(23 \%)$ patients smoked at some point while their valvular prostheses were in place. The mean \pm SD cholesterol level of the explanted patients ( $n$ = 66) was $189 \pm 40 \mathrm{mg} / \mathrm{dL}$, which was significantly higher than the value of $163 \pm 39 \mathrm{mg} / \mathrm{dL}$ in the control group $(P<.0001$, Figure 1$)$. The mean serum cholesterol level is still in the high normal range for North Americans, implying that calcification might still occur in the high normal range, which is consistent with vascular atherosclerosis. Four (6.1\%) patients were taking statins during the period of valve function versus $12(18 \%)$ patients in the control group $(P=.018)$. Coronary artery disease, presence of hypertension, presence of diabetes mellitus, and smoking status were not significantly different between patients and control subjects (Table 3 ). 
TABLE 2. Significance and correlations of cohort analysis

\begin{tabular}{lcc}
\hline & Spearman correlation, $\boldsymbol{\rho}$ & $\boldsymbol{P}$ value \\
\hline Calcification vs implant age & -0.205 & $.014^{*}$ \\
Calcification vs cholesterol average & 0.176 & $.035^{*}$ \\
Calcification vs valve type & -0.015 & .85 \\
Calcification vs coronary artery disease & & $\boldsymbol{P}$ value, Wilcoxon rank sum test \\
Calcification vs diabetes mellitus & $.017^{*}$ & .069, trend \\
Calcification vs aortic-mitral position & & .367 \\
Calcification vs hypertension & & .414 \\
Calcification vs smoking & & $.57(.49)$ \\
Calcification vs sex & & .938 \\
\hline & Stepwise multiple regression, $\boldsymbol{\beta}$ & $\boldsymbol{P}$ value \\
\hline Implant age & -0.012 & .18 \\
Cholesterol, mean serum & 0.189 & $.02^{*}$ \\
Diabetes mellitus & -0.09 & .30 \\
Coronary artery disease & -0.078 & .37 \\
\hline
\end{tabular}

${ }^{*} P<.05$.

TABLE 3. Case-control analysis

\begin{tabular}{|c|c|c|c|}
\hline \multirow[b]{2}{*}{ Parameter } & Control subjects (no failure) & Patients (valve failure) & \multirow[b]{2}{*}{$P$ value } \\
\hline & Mean (SE, range) & Mean (SE, range) & \\
\hline Age at implantation (y) & $57.7,(1.7,21-79)$ & $57.6(1.7,24-79)$ & Matched, .29 \\
\hline $\mathrm{N}$ & 66 patients & 66 & Matched \\
\hline Valve follow-up (y) & $7.3(0.3,1-9)$ & $7.3(0.3,1-9)$ & Matched, .47 \\
\hline \multirow[t]{2}{*}{ Valve position } & 43 aortic $(65 \%)$ & 43 aortic $(65 \%)$ & Matched \\
\hline & 23 mitral $(35 \%)$ & 23 mitral $(35 \%)$ & \\
\hline \multirow[t]{2}{*}{ Sex } & 27 male $(41 \%)$ & 32 male $(48 \%)$ & $.39 *$ \\
\hline & 39 female $(59 \%)$ & 34 female $(52 \%)$ & \\
\hline Cholesterol average & $\begin{array}{l}163(39 \mathrm{sd}, 73-314=\text { range } \\
\quad \text { median }=162, \text { mode }=163)\end{array}$ & $\begin{array}{l}189 \text { (40 sd, 103-293 range, } \\
191=\text { median, } 175=\text { mode) }\end{array}$ & 2-tailed $t$ test paired for means ${ }^{*} \dagger$ \\
\hline Diabetes mellitus & 11 patients $(17 \%)$ & 17 patients $(26 \%)$ & .13 \\
\hline Hypertensive & 41 patients $(62 \%)$ & 42 patients $(64 \%)$ & .29 \\
\hline Statin use & 12 patients $(18 \%)$ & 4 patients $(6 \%)$ & $.018^{*} \dagger$ \\
\hline Coronary artery disease & 30 patients $(46 \%)$ & 33 patients $(50 \%)$ & .30 \\
\hline Smoker & 14 patients $(21 \%)$ & 15 patients $(23 \%)$ & $.936^{*}$ \\
\hline $\begin{array}{l}\text { Odds ratio for re-replacement, } \\
\text { serum cholesterol }>200 \mathrm{mg} / \mathrm{dL}\end{array}$ & Referent & 3.9 & (95\% confidence interval, 1.7-8.9) \\
\hline \multirow[t]{6}{*}{ Classification of valve failure } & Not applicable & Leaflet tear, 35 patients $(53 \%)$ & \\
\hline & & Degeneration, 24 patients $(36 \%)$ & \\
\hline & & Bacterial endocarditis, 4 patients & \\
\hline & & $(6.1 \%)$ & \\
\hline & & Paravalvular leak, 1 patient $(1.5 \%)$ & \\
\hline & & Other, 2 patients $(3 \%)$ & \\
\hline
\end{tabular}

*Two-tailed $t$ test.

tSignificant at $P<.05$.

Because patients represent an earlier cohort on average than control subjects by 6 years, we performed 2 additional analyses to rule out potential sources of bias. In one subgroup analysis all patient pairs in which one or both patients were taking statins were removed from analysis (data not shown). In another analysis matching was performed by comparing valves matched and implanted during the same year (including matched at position and age of patient, Table 4). The results of both these analyses demonstrate that cholesterol levels are significantly higher in patients (explanted valve patients) than in control subjects.

We removed patient pairings in which one or both of the patients were taking statins because these drugs might influence calcification of the valve. A total of 16 paired groups 
(12 control subjects and 4 patients, 32 in total) were removed, and the results were reanalyzed to exclude possible confounding effects of statins on the results. Patients were still matched for position of valve and age of implantation, as well as duration of survival. The mean cholesterol difference between groups was still highly significant $(P<$ .00001 ; patients, $190.8 \mathrm{mg} / \mathrm{dL}$; control subjects, $158.5 \mathrm{mg} /$ $\mathrm{dL})$. There was no significant difference between groups in terms of diabetes, hypertension, sex, smoking, or coronary artery disease.

We also matched patients for the same year of implantation surgery, age at implantation, and valve position (aortic vs mitral). This effectively removed any influence of possible changing medical-surgical practices through time, although it limited our analysis to 22 patients (Table 4). There was still a significant difference in the mean serum cholesterol levels between patients and control subjects $(187 \mathrm{mg} / \mathrm{dL}$ in patients and $155 \mathrm{mg} / \mathrm{dL}$ in control subjects; $P=.047$, paired $t$ test $)$. Diabetes $(P=.059)$, hypertension $(P=.67)$, smoking $(P=.37)$, coronary artery disease $(P=$ $.34)$, and statin use $(P=.96)$ were not significantly different between the 2 subgroups.

For the complete case-control analysis, the odds ratio for valvular re-replacement in patients whose serum cholesterol levels were greater than $200 \mathrm{mg} / \mathrm{dL}$ was $3.9 \times(95 \%$ confidence interval, 1.7-8.9; Table 3).

\section{Discussion}

We have demonstrated for the first time that increasing serum cholesterol levels are associated with increased bioprosthetic valvular calcification. Furthermore, patients who had their valves explanted had higher serum cholesterol levels than an age-, duration of survival-, and positionmatched group with unexplanted valves (189 vs $163 \mathrm{mg} / \mathrm{dL}$, $P<.0001)$. Finally, the odds ratio for valve explantation and re-replacement was 3.9-fold higher in patients whose serum cholesterol levels were greater than $200 \mathrm{mg} / \mathrm{dL}$.

It is controversial whether increased serum lipid levels correlate with the progression of peripheral atherosclerosis, coronary calcification, and native aortic valve sclerosis. ${ }^{4,10,11}$ Pohle and colleagues ${ }^{6}$ recently demonstrated that the rate of change of both coronary and native aortic valve calcification progresses more rapidly in individuals whose serum LDL levels are greater than $130 \mathrm{mg} / \mathrm{dL}$. Palta and coworkers $^{12}$ also demonstrated that those with a serum cholesterol level of greater than $200 \mathrm{mg} / \mathrm{dL}$ had a rate of native aortic valve area reduction roughly twice that of those with a lower cholesterol level $(P=.04)$.

In this cohort study we demonstrate that blood pressure, sex, and smoking are not linked to tissue valve calcification. We also demonstrate that coronary calcification is linked to tissue valve calcification; thus what is harmful to the coronary arteries might be harmful for tissue valves, and what is

\section{SERUM CHOLESTEROL $(\mathrm{mg} / \mathrm{dl})$}

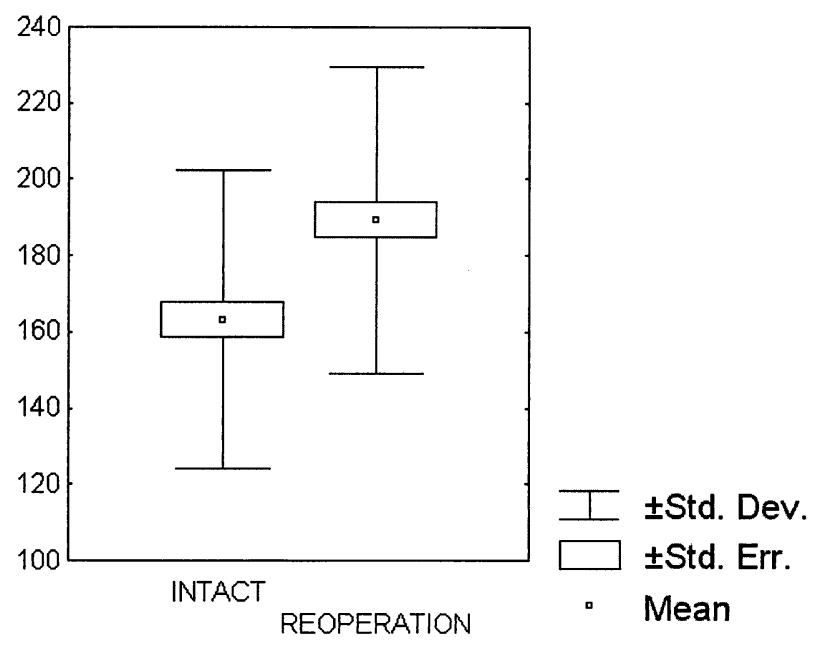

Figure 1. Plot of mean serum cholesterol levels in the group of patients whose valves remained intact (control group) versus those undergoing reoperation (explanted). Groups were matched for age of patient at implantation, sex, and duration of valve survival.

protective of the coronary arteries might be protective of the valves. Prior reports have concluded that tissue valves are appropriate for patients undergoing mitral valve replacement with coronary artery disease who are more than 60 years of age and for aortic valve replacement in patients who are more than 70 years of age, irrespective of coronary artery disease. ${ }^{13}$ Patients with subcritical coronary disease who undergo tissue valve replacement might be candidates for statin therapy.

Younger age has previously been demonstrated as a risk factor for leaflet failure. ${ }^{1,14-16}$ In our study younger age was linked to increasing calcification. Interestingly, the absolute magnitude of the linear association $(\rho=0.205, P=.014)$ was similar for younger patients as for cholesterol $(\rho=$ $0.176, P=.035$ ), implying that the contribution of cholesterol to calcification of the valve is of a similar importance as younger age. In our study diabetes, a well-documented risk factor for atherosclerosis, demonstrated a trend $(P=$ .069) toward significance in univariate analysis. Patients were considered diabetic if they were being actively medically treated, and thus our study might have missed some patients with untreated diabetes. Also, our limited numbers might not have had adequate power to elicit the contributions of these other risk factors for atherosclerosis on valvular calcification.

Bellamy and associates, ${ }^{17}$ however, recently reported that there was no correlation between the rate of progression of aortic stenosis with cholesterol levels in 157 patients with aortic stenosis. Statin therapy, however, was associated with 
TABLE 4. Analysis of case-control matching for year of implantation, age at implantation, and valve position

\begin{tabular}{|c|c|c|c|}
\hline & $\begin{array}{l}\text { Patients (valve } \\
\text { reoperation) }\end{array}$ & $\begin{array}{l}\text { Control } \\
\text { subjects }\end{array}$ & $P$ value \\
\hline $\mathrm{n}$ & 11 & 11 & Matched \\
\hline Implant year & 1993.9 & 1994 & .17, paired $t$ test \\
\hline Implant age & 58 & 59 & Matched \\
\hline Position & 9 aortic, 2 mitral & 9 aortic, 2 mitral & Matched \\
\hline Mean serum cholesterol level (mg/dL) & $187 \mathrm{mg} / \mathrm{dL}$ & $155 \mathrm{mg} / \mathrm{dL}$ & .047 , paired $t$ test \\
\hline
\end{tabular}

a decreased rate of progression of stenosis-sclerosis of the aortic valve. In that study the authors confirmed that aortic stenosis progresses with a reduction in orifice size of approximately $0.1 \mathrm{~cm}^{2} / \mathrm{y}$ in patients who are not receiving statin therapy. For those receiving medical therapy, the decrease in mean aortic valve area measured was only 0.04 $\mathrm{cm}^{2} / \mathrm{y}$, which is approximately half the native rate. Palta and coworkers $^{12}$ also documented a near doubling of the rate of aortic valve area reduction in those whose serum cholesterol levels were greater than $200 \mathrm{mg} / \mathrm{dL}$. After adjustment for sex, age, and baseline aortic valve area, statin therapy remained protective, although cholesterol levels during statin therapy showed no correlation with the progression of aortic stenosis. ${ }^{17}$ Both Novaro and colleagues ${ }^{18}$ and Aronow and associates $^{19}$ also reported similar results that statin-treated groups had a slower rate of aortic stenosis progression. Shavelle and coworkers ${ }^{9}$ have documented that patients receiving statins have a diminished rate of accumulation of aortic valve calcium, as assessed by means of electron beam computed tomography, although serum cholesterol levels were not available. It is an intriguing finding that the effects of the statins are not solely attributable to lipid-lowering effects. This is not without precedent because the statins have been shown to stabilize plaques as part of the beneficial effect in preventing cerebrovascular occlusion and in reducing inflammation. Currently, there is no information on the rate of progression of bioprosthetic valve sclerosis with statin therapy. In our case-control study patients whose valves were not explanted had a higher incidence of statin use than those whose valves were explanted (18\% vs $6 \%, P$ $=.018$ ). Some patients might have been started on statins in the midst of their valve use. This prompted reanalysis with all statin pair groups removed. The mean serum cholesterol level was still higher $(190.8$ vs $158.5 \mathrm{mg} / \mathrm{dL}, P<.0001)$ when the confounding effects of statins were removed. We also matched patients so that operations occurred in the same year while keeping the age of the patient at implantation and position matched and found the explanted valve group to have a higher serum cholesterol level than the control subjects (187 vs $155 \mathrm{mg} / \mathrm{dL}, P=.047$ ).

The correlation of increased cholesterol levels with bioprosthetic valvular calcification invites mechanistic speculation..$^{5}$ Eliminating lipids from tissue valves by means of ethanol extraction prevents in vivo calcification. ${ }^{20}$ It is possible that glutaraldehyde-fixed valves have the appropriate physical characteristics to serve as a nidus for crystallization. Another potential mechanism is the migration of cells into the matrix of the valve. Blood-borne progenitor cells that are capable of differentiating into various lineages from the marrow might have the ability to deposit matrix, which can calcify. Additionally, oxidized LDL, which colocalizes with $\mathrm{T}$ lymphocytes and calcium, has been demonstrated in nonrheumatic stenotic aortic valves. ${ }^{21}$ Older literature had documented that silicone rubber prostheses in the Starr-Edwards valve (Edwards Lifesciences, Irvine, Calif) absorb lipids. ${ }^{22}$ Ferrans and associates ${ }^{23}$ had documented that cholesterol ester crystals were found in porcine aortic valves that had been implanted in the mitral position for 8 years.

This study has its limitations. It is retrospective, and the population for the cohort study is selected for patients who required reoperation. Patients who did not undergo reoperation were not included in the cohort study, although we attempt to address this in the case-control study. One could attempt to address this by using electron beam computed tomography to measure the progression of calcification over time in tissue valves. Serum cholesterol values were used rather than LDL levels. Smoking was self-reported.

In summary, we have shown in a retrospective cohort and case-control study that cholesterol might contribute to bioprosthetic valve calcification, which might lead to valve re-replacement. A randomized prospective clinical trial to determine whether statins prevent bioprosthetic valve calcium accumulation is warranted.

We thank Dr Fred Schoen of the Department of Pathology at the Brigham and Women's Hospital for his review of this manuscript. We also thank Dr Farzad Mostashari for his statistical review of this manuscript.

\section{References}

1. Cohn LH, Collins JJ Jr, Rizzo RJ, Adams DH, Couper GS, Aranki SF. Twenty-year follow-up of the Hancock modified orifice porcine aortic valve. Ann Thorac Surg. 1998;66(suppl):S30-4.

2. Jamieson W, Burr L, Munro A, Miyagishima R. Carpentier-Edwards standard porcine bioprosthesis: a 21-year experience. Ann Thorac Surg. 1998;66(suppl):S40-S43. 
3. Schoen FJ. Cardiac valve prostheses: review of clinical status and contemporary biomaterials issues. J Biomed Mater Res. 1987;21:91117.

4. Mohler ER 3rd. Are atherosclerotic processes involved in aortic-valve calcification? Lancet. 2000;356:524-5.

5. Demer LL. Cholesterol in vascular and valvular calcification. Circulation. 2001;104:1881-3.

6. Pohle K, Maffert R, Ropers D, et al. Progression of aortic valve calcification: association with coronary atherosclerosis and cardiovascular risk factors. Circulation. 2001;104:1927-32.

7. Callister TQ, Raggi P, Cooil B, Lippolis NJ, Russo DJ. Effect of HMG-CoA reductase inhibitors on coronary artery disease as assessed by electron-beam computed tomography. $N$ Engl J Med. 1998;339: 1972-8.

8. Bild D, Folsom A, Lowe L, et al. Prevalence and correlates of coronary calcification in black and white young adults: the coronary artery risk development in young adults (CARDIA) study. Arterioscler Thromb Vasc Biol. 2001;21:421-6.

9. Shavelle D, Takasu J, Budoff M, Mao S, Zhao X, O'Brien KD. HMG CoA reductase inhibitor (statin) and aortic valve calcium. Lancet. 2002;359:1125-6.

10. Pearlman A. Medical treatment of aortic stenosis: promising or wishful thinking. J Am Coll Cardiol. 2002;40:1731-4.

11. O'Brien MF. What is the progression of aortic valve stenosis (bicuspid, congenital, acquired, degenerative)? Can this progression be modified by statin therapy? Is "prophylactic" AVR for mild AS indicated during CABG? Presented as an abstract at the American College of Cardiology, Hawaii, February 2003. American College of Cardiology; 2003.

12. Palta S, Pai AM, Gill KS, Pai RG. New insights into the progression of aortic stenosis: implications for secondary prevention. Circulation. 2000;101:2497-502.

13. Jones EL, Weintraub WS, Craver JM, Guyton RM, Shen Y. Interaction of age and coronary disease after valve replacement: implication for valve selection. Ann Thorac Surg. 1994;58:378-85.

14. Kirklin JK, Smith D, Novick W, et al. Long-term function of cryopreserved aortic homografts: a ten-year study. J Thorac Cardiovasc Surg. 1993;106:154-66.

15. Cleveland D, Williams W, Razzouk A, et al. Failure of cryopreserved homograft valved conduits in the pulmonary circulation. Circulation. 1992;86(suppl):II150-3.

16. Miller D, Stinson E, Oyer P, et al. The durability of porcine xenograft valves and conduits in children. Circulation. 1982;66(suppl):I172-85.

17. Bellamy M, Pellika P, Klarish K, et al. Association of cholesterol levels, hydroxymethylglutaryl coenzyme-A reductase inhibitor treatment, and progression of aortic stenosis in the community. J Am Coll Cardiol. 2002;40:1723-30.

18. Novaro GM, Tiong IY, Pearce GL, Lauer MS, Sprecher DL, Griffin BP. Effect of hydroxymethylglutaryl coenzyme A reductase inhibitors on the progression of calcific aortic stenosis. Circulation. 2001;104: 2205-9.

19. Aronow W, Ahn C, Kronzon I, Goldman M. Association of coronary risk factors and use of statins with progression of mild valvular aortic stenosis in older persons. Am J Cardiol. 2001;88:693-5.

20. Vyavahare NR, Jones PL, Hirsch D, Schoen FJ, Levy RJ. Prevention of glutaraldehyde-fixed bioprosthetic heart valve calcification by alcohol pretreatment: further mechanistic studies. J Heart Valve Dis. 2000;9:561-6.

21. Olsson M, Thyberg J, Nilsson J. Presence of oxidized low density lipoprotein in nonrheumatic stenotic aortic valves. Arterioscler Thromb Vasc Biol. 1999;19:1218-22.

22. Chin H, Harrison E, Blankenhorn D, Moacanin J. Lipids in silicone rubber valve prostheses after human implantation. Circulation. 1971; 43/44(suppl):I51-6.

23. Ferrans VJ, McManus B, Roberts WC. Cholesteryl ester crystals in a porcine aortic valvular bioprosthesis implanted for eight years. Chest. 1983;83:698-701.

\section{Discussion}

Dr D. Craig Miller (Stanford, Calif). I congratulate Dr Farivar and Dr Cohn for bringing something to our attention that may prove to be very important in the future. Certainly it is scientifically much more appealing than what some of you in the room may be old enough to remember. In the late 1970s and early 1980s, Don Magilligan and others were saying, "We're only going to get so many heartbeats out of these tissue valves. Why don't we use $\beta$-blockers and slow down their heart rates? Maybe the valves would last longer." Those were the old days. This is very promising and exciting, and it stems from the work being done in the native aortic valve in elderly patients with aortic sclerosis, where Emile Moeller at Penn and his vascular biology colleagues think they are going to take another operation away from us. But don't get too paranoid, because the very promising work in elderly patients with aortic sclerosis does not apply to younger patients with calcific aortic sclerosis, in whom the valve was originally a bicuspid valve. In fact, at the American Heart Association meeting in 2002, Dr Moeller said that the Penn Institutional Review Board believed it was unethical to randomize large cohorts of patients with native valve aortic sclerosis. The uncontrolled data had already proved to their satisfaction that statins retard progression of aortic sclerosis. I personally do not think that has been proven conclusively, but that is what Moeller relayed. In any event, there has been no information, until the material you just heard, about what happens when patients with bioprosthetic valves are treated with statins.

This paper was submitted early and actually has already been revised and accepted for publication in the Journal by Andrew Wechsler. Tirone David has written an editorial pertaining to this paper and a similar one from Germany by Nollert and associates concerning the effects of hyperlipidemia on the durability of the Hancock pericardial valve. Both papers will be fast-tracked because the Editor believes this question is important.

Tirone David looked at 635 old Hancock I valves from Stanford implanted in the 1970s and 1980s and observed for 15 years or more. He could show no adverse impact of hyperlipidemia on structural valve deterioration (SVD). He then looked at 913 patients undergoing aortic valve replacement at the Toronto General Hospital in the 1990s (Hancock II, Carpentier-Edwards pericardial, and Toronto SPV) and again could find no apparent adverse influence of hyperlipidemia on SVD.

Some of you may have been wondering why the freedom from SVD curves in Toronto with any kind of tissue valve are so good. Tirone himself has admitted that maybe it is because in Ontario almost everybody is already on a statin; maybe they never will see an effect there in their more recent patients. Another factor pertaining to the mitral position is that only the very sickest and very elderly patients undergo mitral valve replacement with a tissue bioprosthesis; the majority of valves are repaired.

In any event, this is promising work, even though it is just the first step. I do have one statistical question: When you get down to the case match controls, exclude the statin matches, and then you rematch for age, you get to some very small Ns. How does this affect the reliability of your statistics?

My real question is this: What is the next step? How are we going to confirm that this is true or not in larger, multicenter analyses? Tell us where you are headed. In today's world, at least in California, it appears that almost everybody is already on atorvastatin calcium (Lipitor) or some statin, even if they do not have coronary disease; therefore, how can you ever hope to test 